\title{
Social Science as a Guide to Social Metaphysics?
}

\author{
Katherine Hawley ${ }^{1}$
}

Published online: 5 February 2018

(C) The Author(s) 2018. This article is an open access publication

\begin{abstract}
If we are sympathetic to the project of naturalising metaphysics, how should we approach the metaphysics of the social world? What role can the social sciences play in metaphysical investigation? In the light of these questions, this paper examines three possible approaches to social metaphysics: inference to the best explanation from current social science, conceptual analysis, and Haslanger-inspired ameliorative projects.
\end{abstract}

Keywords Social science $\cdot$ Social ontology $\cdot$ Social metaphysics $\cdot$ Scientific realism $\cdot$ Conceptual analysis $\cdot$ Ameliorative

\section{Introduction}

Philosophical debates about the epistemic relationship between science and metaphysics typically focus upon the natural sciences, especially fundamental physics. Naturalisers argue that discussions of the metaphysics of space, time, causation, composition and identity are fruitless, incomplete, or naïve unless they are closely guided by contemporary scientific opinion. And the scientific opinions which matter are primarily those of physicists. This quest for scientifically determined — or at least scientifically informed-metaphysics has both positive and negative motivations. Positive: physics can be pictured as moving from one success to another, bringing technological revolutions in its wake, and opening up realms of the tiny, the enormous, and the spatio-temporally distant to previously unimaginable empirical investigation. Negative: given this onward march to the broad, sunlit uplands, it becomes more and more difficult to understand how a priori, conceptual, or armchair strategies could possibly rival physics in helping us grasp the deep

Katherine Hawley

kjh5@st-andrews.ac.uk

1 Department of Philosophy, University of St Andrews, Edgecliffe 212, The Scores, St Andrews, Fife KY16 9AL, UK 
structure of reality. On this picture, if metaphysics is possible at all, it must be pursued through close engagement with science.

What does such engagement mean in practice? As I discussed in Hawley (2006), drawing on Sklar (1981) and French (1998), there is little prospect of simply 'reading off' a metaphysical picture from current physical science; moreover it is a mistake to think that scientists enter into theory-building without any metaphysical presuppositions whatsoever. Even those who advocate a more naturalised approach to metaphysics acknowledge that there is much to negotiate here (Callender 2011, and see Schrenk 2017, ch. 7 for an introduction to the issues).

Despite these difficulties, we cannot ignore the fact that scientists often seem to be discussing topics which have traditionally fallen within the purview of metaphysicstopics such as time, space, matter, causation, and composition. In light of this, it would seem perverse to neglect what the scientists have to say, even if we do not take contemporary science to be the last word on these traditional topics. In setting out his naturalising approach, Maudlin writes:

The basic idea is simple: metaphysics, insofar as it is concerned with the natural world, can do no better than to reflect on physics. Physical theories provide us with the best handle we have on what there is, and the philosopher's proper task is the interpretation and elucidation of those theories. In particular, when choosing the fundamental posits of one's ontology, one must look to scientific practice, rather than to philosophical prejudice. $(2007,1)$

It is beyond the scope of the present paper to assess a naturalising project such as Maudlin's, which is clearly directed towards physics. Whilst the details are complex and contentious, it is not difficult to see in outline how understanding scientific theories of space-time and gravitation should help us answer traditional metaphysical questions about space and time; likewise we can see in outline how understanding subatomic physics should help us answer traditional metaphysical questions about composition, substance, and matter.

Instead, I want to explore the possibilities for an equivalently naturalising approach to the metaphysics of the social world. We can't straightforwardly extract such a metaphysics from physics, no matter how impressed we may be by Maudlin. Nothing in Einstein's field equations will tell us whether there are social groups and what their membership criteria are, what sort of entity the UK Labour party really is, what constitutes a marriage, and whether there are races and/or genders.

More abstractly, metaphysicians of the social world ask, for example, what social groups there are, and how they act and are acted upon. Are some social institutions identical to social groups; if not, what are they? How do institutions persist through time? How do social facts arise from non-social facts? Do facts about individual mental states form a complete supervenience base for social facts? Are (some) social kinds natural kinds? (The papers in Schmitt (ed.) 2003 provide a good sample of philosophical work on these topics.) It's difficult to see how we could even begin to answer any of these questions by engaging with basic physics.

Some dedicated naturalisers may be tempted by a radical eliminativism about the social. If we combine fundamental physics with a philosophical assertion of radical reductionism, then we may be able to deduce that there is really no such thing as a social group, the Labour Party, a marriage, or a race. But physics alone won't do it, in the absence of a philosophical 'that's all, folks' claim: the eliminativist naturaliser must find an acceptable philosophical method which will enable her to reason to such a position. And, like 
other eliminativists, she seems to owe us an account of the facility with which we speak and think about the social world, despite its alleged non-existence. (Barnes 2014 discusses social metaphysics in connection with issues of fundamentality.)

If this seems too daunting, we may pursue an alternative approach to naturalising social metaphysics. If we conceive of the naturaliser as someone who is not myopically dedicated to fundamental physics, but is rather an admirer of scientific methods or empirical study more generally, we would expect her to look to the social sciences to provide us with a metaphysics for the social world. Just as the natural sciences provide us with epistemic access to the non-social elements of reality, the naturaliser may argue that our best chance of learning about the entities and relationships which constitute social reality is to investigate the social sciences.

In this paper, I will assume a broadly science-driven approach to the metaphysics of the non-social world, and on that basis examine some issues which arise when we attempt to extend that naturalising approach to the metaphysics of the social world. For the most part I will be comparing and contrasting social sciences and social metaphysics with the science and associated metaphysics of relatively fundamental physics. In so doing I neglect a rich and important literature concerned with the biological, the chemical and the non-fundamental physical: some issues which arise in connection with the social sciences mirror those arising from these other sciences, but some are distinctively different.

\section{Pessimism and Naturalised Social Metaphysics}

Can we compare the relationship between social science and social metaphysics to the relationship between natural science and non-social metaphysics? Unfortunately, there is no uncontroversial account of how natural science should influence or determine metaphysics even in the clearest cases, and different naturalisers will take different approaches. But one attractive option is to see the naturalising metaphysician of the natural sciences as a kind of scientific realist, who uses inference to the best explanation to move from the empirical successes of a scientific theory to the accuracy of the metaphysical picture embedded in the theory (Hawley 2006). Typically no metaphysical picture is straightforwardly entailed by a given scientific theory, so this notion of 'embedding' is contentious. Moreover some naturalisers will fear that such uses of inference to the best explanation will too easily take us far beyond scientifically-respectable metaphysics. Nevertheless, this is one picture of naturalised metaphysics which allows a significant role for science, without falling into outright scepticism about metaphysics. Can this picture accommodate social metaphysics?

As is familiar, anti-realists have forced scientific realists into a careful delimitation of the proper uses of inference to the best explanation. For example, the pessimistic induction (Laudan 1981) begins with the claim that the history of the natural sciences is replete with theories which were empirically successful for a while, but ultimately proved to be metaphysically misguided: prominent villains of this piece include the caloric theory of heat, the phlogiston theory of chemistry, and the optical ether, which was supposed to provide a physical medium for light waves. Why should we think that today's physical theories are any better guide to metaphysical truth than those false theories of the past?

In response, realists such as Stathis Psillos (1999) have argued that we should accept the ontological posits of scientific theories only where the relevant science is mature, in the Kuhnian sense, and where the theory in question generates successful novel predictions, in 
a way which centrally involves the ontological posits at stake. Naturalising metaphysicians cannot draw their metaphysical conclusions from just any old scientific theory, but only from those which meet a very high epistemic standard. Given these restrictions, the pessimistic induction has fewer instances to work with: without detailed investigation of the history of science it is not obvious that there really are many examples of successful, mature, novelly-predictive scientific theories which have turned out to be metaphysically misguided in some central way.

Given Psillos-style restrictions on the use of inference to the best explanation, what prospect is there of inferring a social metaphysics from the social sciences? The obvious concern is that social sciences do not in general meet this high epistemic standard, either because as a matter of contingent historical fact they have not yet reached that stage in their development, or because this standard is not an appropriate aspiration for the social sciences. I cannot possibly evaluate the historical state of development and levels of empirical success of the various social sciences-this would be a mammoth task for which I am completely unqualified. However, even at the most superficial level a number of phenomena indicate that the prospects for securely basing social metaphysics via inference to the best explanation from social science are currently faint. I hope that some of these phenomena will seem familiar to the reader, and at least provide a challenge to this picture of naturalised social metaphysics.

First, it is a commonplace that, in comparison to the natural sciences, the social sciences display a much wider internal divergence of methodologies, presuppositions, schools of thought-paradigms, as we might say. This is the case both within individual disciplines, and between disciplines. Whilst there is blurring of disciplinary boundaries within the natural sciences, social scientific disciplines not only merge into one another around the edges, but explicitly treat the same phenomena in different and seemingly incompatible ways.

For example, consider trust and distrust. What does it take for people to trust one another, and what sorts of factors encourage or inhibit trust? These issues can be approached through sociology, economics, social and/or evolutionary psychology, political science, and indeed even through philosophy. Piotr Sztompka's Trust: A Sociological Theory (1999), whilst it encompasses a lot of fascinating material, has a focus on political and societal institutions and structures as determinants of public trust. At the other end of at least one spectrum, neuroeconomist Paul Zak's The Moral Molecule: How Trust Works (2012) recounts his research on the role of the hormone oxytocin in promoting trust. Meanwhile, the papers gathered in Ostrom and Walker (eds.) Trust and Reciprocity (2005) range over game theory, body language, evolutionary theory, incentives, and features of social context.

Such varied richness of paradigms or theoretical approaches directly undermines the possibility of using inference to the best explanation in order to establish an uncontroversial metaphysics of the social world, since the differences often centrally involve disagreement about which categories are explanatorily valuable. For example, how important is social class in explaining social phenomena, and which class taxonomies are most useful for this purpose? How significant are race, or gender? Different social scientists, working in different traditions, will have very different answers to these questions. A naïve approach to naturalised social metaphysics which undertook ontological commitment to those entities explanatorily central to the social sciences as currently practiced would not provide a univocal picture of social reality.

Maybe we should not expect to find a univocal picture of social reality. Standard discussions of the metaphysics of the natural sciences presuppose a kind of ontological 
non-pluralism, an expectation that there is a unified reality which will ultimately be revealed through our best physical theories. And perhaps pluralism is a better bet when it comes to the social realm. However, it does not even seem that the social sciences have reached a stably diverse position, from which metaphysicians could infer something definite, if plural.

Second, it is far from obvious that social scientific theories are well placed to generate successful novel predictions. According to scientific realists in the context of the natural sciences, we should infer ontological claims only from those theories which have generated such predictions; merely accommodating already-familiar data is not good enough (Psillos 1999). This is because, crudely speaking, it seems just too easy to gerrymander a 'theory' to accommodate our existing observations, and so the fact that a theory can account for known data does not reflect positively on its likely accuracy about the unobserved. In contrast, the ability of a theory to make a novel yet accurate prediction-and the more surprising the better-is thought to indicate its proximity to the truth.

Even if we accept that some social scientific theories have enjoyed some empirical success, there simply does not seem to be the track record of novel predictions which so impresses scientific realists about the physical sciences in particular: there are no social analogues of the gravitational waves or Higgs boson which bring physics to the headlines. Even in the physics cases, of course, there are subtle issues about the degree to which such predictions are both novel and successful, and indeed about the relationship between novel predictive success and ontological accuracy. But if these issues are contentious for physics, they do not even arise in the context of the social sciences.

Relatedly, and perhaps more strikingly, there are no social scientific equivalents of the 'marvels of technology' which are, for many, a key impetus for scientific realism-the smartphone, treatments for cancer, or New Horizons images of Pluto. Again, this is not to deny that the social sciences have contributed to improving our standards of living, our understanding of the world, and our ability to imagine alternative social arrangements. But their empirical and technological successes are certainly less vivid, and their failures are hard to ignore; here one thinks of the failure of most economists to predict the global financial crisis of 2008.

Such musings can be read as triumphalist physics-fetishisation, neglecting internal divisions and contingencies within the natural sciences, whilst holding the social sciences to an entirely inappropriate standard. Practitioners of the social sciences do not all aspire to settle on a single paradigm for their discipline, and nor do they all aim at achieving novel predictive success. For many, the goals of understanding and explanation take precedence over the goal of prediction, either through preference or through necessity. Diversity within the social sciences need not be seen as a temporary precursor to a more 'mature' state-it may instead be the best, most appropriate way for the social sciences to function. Such issues about the nature and goals of social science, and about the relationship between social and natural sciences, are traditional staples of debate in the philosophy of social science, as well as within the disciplines themselves.

Indeed, compared to natural scientists, social scientists are relatively open to accepting that they must choose and work with certain philosophical assumptions or frameworks. Training in the social sciences often involves discussion of methodology which takes in high-level issues of ontology, metaphysics and epistemology, as well as more detailed training in specific research methods and tools. The philosophy of social science looms larger in social science education than does the philosophy of physics or chemistry in their corresponding disciplines. There seems little temptation to think that social scientific theories are free of philosophical assumptions, and that they can somehow provide a 
neutral arbiter between rival pictures of social metaphysics. To some extent, the same is true in the natural sciences, but the point is much less controversial for the social sciences.

Thus we should not assume that descriptions of social sciences as pre-paradigmatic, as internally conflicted, or as lacking novel predictive success, inevitably constitute criticisms of those disciplines. Nevertheless, these features present a huge challenge to anyone hoping to extract a metaphysics of the social world from the social sciences by following the example of scientific realist philosophers of physics. We need to look elsewhere if we are to develop a metaphysics of the social world.

\section{Conceptual Strategies for Social Metaphysics}

If we attempt to pursue social metaphysics by copying the methods adopted in naturalised metaphysics of the non-social world, we will not succeed. Instead, we might turn to conceptual analysis, partly on the basis that conceptual work is appropriate and useful exactly when a scientific discipline is in its early stages of development. On this view, conceptual analysis is granted a modest but significant role in debates about social metaphysics, in a ground-clearing, under-labouring way. For example, in the introduction to her On Social Facts, Gilbert positions herself as doing conceptual work: "My primary aim is to make explicit the structure of certain everyday [social] concepts." $(1989,3)$. Gilbert makes a strong case for the importance of this work, whilst examining the rival views of Durkheim and Weber as to the proper role of everyday concepts in social science. More recently, Guala (2007) has very useful discussion of the role of conceptual analysis in social metaphysics.

In the context of metaphysics of the non-social world, 'mere' conceptual analysis is seen as contrasting with approaches which take science more seriously. From the point of view of the naturalising metaphysician, there seems little reason to think that our everyday concepts, which are well-suited to enabling our thought about the superficial features of medium-sized objects, will give us any kind of insight into the ultimate nature of physical reality; after all, science itself has shown us ways in which physical reality is more bizarre than we could possibly have imagined from the armchair.

And indeed those philosophers who are most prominent in conceptual debates around social ontology and social metaphysics do not tend to linger on detailed findings of current social science, though they do sometimes engage with social theorists on methodological issues. For example, leading authors such as Gilbert (1989), Searle (1995), and Tuomela (2002) draw on considerations from the philosophy of mind and action to develop theories of joint intention, group action, and social status. These are tested against relatively simple cases such as a small group of adults taking a walk together, or the question of e.g. what makes a certain piece of paper count as a dollar bill (Epstein 2015 is an interesting critique of this methodology). These are everyday, common sense examples, not complex situations drawing on the detailed findings of social sciences. As such, they are reminiscent of the everyday common sense examples of tables, heaps of sand, and billiard balls which are the staples of so-called 'analytic' rather than 'naturalised' metaphysics in the non-social realm.

What should the naturalising metaphysician make of all this? If conceptual analysis is a poor approach to the metaphysics of the natural world, are there any reasons to think that it is a positively good method for social metaphysics? Does it make sense to welcome 
conceptual analysis in social metaphysics, whilst rejecting it for the metaphysics of the natural world?

I will consider two possible defences of the use of conceptual analysis here. First, we might think that the social realm is in some deep way generated by or grounded in our concepts and intuitions, in a way in which the natural world is not, and therefore that we can get epistemic access to social metaphysics through examination of the concepts and intuitions which help generate it. Second, we might think that, regardless of the grounding issue, our concepts are likely to reflect the contours of the social world, since they have developed in direct response and interaction with that world.

The first of these thoughts does not provide strong support for a distinctive role for conceptual analysis in social metaphysics, because grounding relations are not in general epistemically transparent. Even if our conceptual frameworks are indeed the ontological grounds for the social realm, this does not entail that we can learn much about the social realm by studying concepts. Analogously, even if fundamental particles and their interrelations are the ultimate ontological ground of biological existence, this does not entail that we can learn much about the biological realm by studying such particles.

In order to make epistemic use of the supposed grounding relations between social reality and our concepts, we would need to understand much more about those relations themselves. Indeed, this is one natural way in which to understand the recent work of Searle, Gilbert, Tuomela and others. For example, on the opening page of his Making the Social World Searle writes "I attempt to explain the exact role of language in the creation, constitution, and maintenance of social reality" (2010, ix). The title of Gilbert's (2013) Joint Commitment: How We Make the Social World-makes clear that it is our joint commitments which give rise to social reality. Both Searle and Gilbert present rich, complex pictures, which differ from one another in important ways. Yet each is offering an account of how social metaphysical states of affairs are generated by our mental and/or linguistic actions. It is only when such a project is fully achieved that we can hope to infer from what we say and judge to the nature of the social realm.

What about the second thought, that we can expect our concepts and intuitions to reflect the social world at least approximately, since they have developed in response to it? This seems a more promising strategy for vindicating the extensive use of conceptual analysis in social metaphysics whilst rejecting it for the metaphysics of the natural world. In discussions of metaphysics and physics, one compelling objection to the use of conceptual analysis and everyday intuitions is that whilst those intuitions and concepts evolved (biologically or culturally) to fit the macroscopic, low-speed world of medium-sized dried goods, current science tells us that concepts suitable for those familiar domains are worse than useless at other scales.

In contrast, we might think, our social intuitions and social concepts have developed through our interactions with the very social world which our social metaphysics attempts to capture, and so there is good reason to think that they will be accurate. Indeed, we can recognise a distinctive two-way interaction between our social concepts and the social world. On the one hand, we adapt and develop our concepts in response to that world. And on the other, the social world may be responsive to our concepts of it, at least in certain cases. In a number of studies (e.g. 1995), Ian Hacking has explored the ways in which social category concepts can influence the nature of the people categorised: we the people often respond to the labels which are attached to us, in a way in which natural phenomena do not (Cooper 2004 raises significant criticisms of Hacking).

On this line of thinking, our everyday social concepts might fail us when we try to understand a social world very distant from our own, but for the purposes of understanding 
our own societies, at least, we can be more confident that our concepts reflect reality. I think that there is something to this. Nevertheless, we need to proceed with caution, for several reasons. First, philosophical work on standpoint epistemology and epistemologies of ignorance has highlighted ways in which those who wield power in society often lack insight into aspects of social organisation which are obvious to those lower down the hierarchy. For Charles W. Mills, white ignorance of the detail and oppressive nature of racial structures in society is not a mere accident; instead, Mills argues that it is a necessary element of continuing racial inequalities which favour those who are ignorant (2007). Focusing primarily on gender, Sandra Harding argues that "members of oppressed groups have fewer interests in ignorance about the social order and fewer reasons to invest in maintaining or justifying the status quo than do dominant groups" $(1991,26)$.

In different ways, both Mills and Harding indicate that the concepts which enable the powerful to succeed in the social world may not accurately reflect the nature of that world, indeed that the usefulness of such concepts often crucially depends upon their inaccuracy. We can grasp this even in cases not focused on race or gender. For example, Margaret Thatcher's (in)famous claim that "there is no such thing as society, there are individual men and women and there are families" may seem more plausible to those who are either self-sufficient or have strong family support, and so do not need to rely upon society at large (or at least do not perceive themselves as relying upon society). Since many or most people who are professionally engaged in social science and social metaphysics are relatively powerful in relevant respects, there is a systematic risk that when we pursue social metaphysics via analysis of 'our' concepts, we will generate an inaccurate picture of social reality.

Moreover, even if we somehow managed to take divergent perspectives fully into account, we would need to acknowledge that our concepts are unlikely to be a perfect reflection of social reality. Indeed, one role for social science is to investigate potential gaps between both scientific and popular views of social reality, and that reality itself. For example, in 2014 the Guardian newspaper reported on social scientific research showing that on average UK citizens think that $20 \%$ of the population is Muslim, whereas the true figure is 5\%; the 'perception gap' is even wider in France and Belgium. Across European countries there were differing widespread yet inaccurate opinions about levels of crime, teenage pregnancy, religious affiliation, and many other social phenomena. (http://www. theguardian.com/news/datablog/2014/oct/29/todays-key-fact-you-are-probably-wrongabout-almost-everything)

Such concrete misperceptions concern the extensions rather than the intensions of our social concepts. Nevertheless, this reminds us that one important role for the social sciences is to investigate the accuracies and inaccuracies of our 'common sense' pictures of social reality. As in the physical sciences, what may seem obvious to us pre-reflectivelyor even after much armchair reflection-may be revealed to be false. There is no vicious circularity involved when we invoke the findings of social science to correct our ordinary social 'insights'. Nevertheless, if we propose to investigate social metaphysics through investigating our concepts of the social realm, we will need to be alert both to the varieties of such concepts, but also to the potential feedback loops emerging from our practice of using social science-with the conceptual frameworks implicit there-to investigate the nature and accuracy of our social ways of thinking.

Despite these formidable obstacles and obscurities, however, there seems less risk of a complete disconnect between concept and reality in the social realm than in our common sense picture of the physical world. Our ordinary understanding of social reality is flawed and partial, but the gap between perception and reality is surely not as big as the gap 
between our ordinary concepts of physical objects, and the picture provided by quantum theory. Thus, those who are suspicious of conceptual methods as applied to the metaphysics of the natural world may be somewhat more optimistic about the corresponding methods as applied to the metaphysics of the social world, so long as they proceed with caution.

\section{Social Science and Ameliorative Projects}

I have rejected the project of inferring a social metaphysics from the social sciences in anything like the way that naturalisers hope to infer metaphysics from the natural sciences. But I have suggested that naturalisers should be more positive about the use of conceptual analysis in the social realm, compared to the use of conceptual analysis as a way of investigating the metaphysics of the non-social. In this section, I will briefly discuss an alternative approach to social metaphysics, one which distances itself both from conceptual analysis and from 'scientific' approaches, but which nevertheless creates a distinctive role for the social sciences within social metaphysics.

In a sequence of important papers, collected in her (2012), Sally Haslanger has distinguished 'conceptual', 'descriptive' and 'ameliorative' philosophical approaches to social categories such as race and gender. She writes:

Conceptual analyses elucidate 'our' (manifest) concept of F-ness by exploring what 'we' take F-ness to be...

Descriptive analyses elucidate the empirical kinds...into which 'our' paradigm cases of F-ness fall...

Ameliorative analyses elucidate 'our' legitimate purposes and what concept of F-ness (if any) would serve them best... Normative input is needed. $(2012,376)$

Although the match is not exact, the descriptive and conceptual approaches very roughly correspond to the projects I explored in earlier sections (Haslanger herself makes further distinctions within these categories); I focus now on the ameliorative approach.

An ameliorative project aims to articulate what concepts 'we' ought to have, given our goals and values, rather than merely uncovering the nature of the concepts 'we' do in fact have. Whilst in principle we might explore ameliorative projects with respect to the nonsocial world, such projects are most at home within the social world, for several reasons.

First, there is the thought that adopting new concepts may change the social world-for better or for worse-either through a Hacking-style causal mechanism, whereby people respond to the concepts applied to them, or more constitutively, in whatever way our concepts and judgements help generate the social world, as investigated by Gilbert and by Searle. Second, in concrete cases, our normative concerns typically target the social realm, taking in natural phenomena insofar as they are implicated in social situations. Haslanger's examples of concepts we might attempt to ameliorate include 'parent', 'tardiness' (in the sense of being late for school or work), and 'bachelor', alongside her central cases of race and gender categories.

What role is there for social science in this picture? A first thought is that if our goals are ameliorative then social science will not be our best source of insights, not even if and when the social sciences achieve stable empirical success. A successful science of a domain provides information about the nature of that domain. But it seems we need not be 
constrained by such scientific findings if our goal in establishing a social metaphysics is not primarily that of accurately describing existing reality. If we pursue an ameliorative project, we are not concerned with how things are, but how they ought to be, and it seems that even the most successful science cannot simply tell us how things ought to be.

Despite these doubts, I think that there is a significant role for social science to play in supporting ameliorative projects within social metaphysics. As Haslanger makes clear, to pursue such projects we need to understand our goals, and how to achieve them; both of these tasks require empirical input alongside armchair reflection, and I will discuss them in turn.

First, we need to establish what 'our' legitimate purposes are. Haslanger's use of scare quotes reminds us to reflect upon who is involved in these conversations: who are 'we'? But in addition to such concerns about diversity, the very notion of conceptual change or replacement indicates that this is not a project any of us can undertake individually: if my goals are very different from everyone else's goals, I cannot hope to further them by single-handedly imposing conceptual revolution on the rest of you. (Even the most powerful dictator needs to rely upon a professional thought-police force.) So no matter who 'we' are, understanding 'our' purposes will require, at the very least, some conversation, and if it is to be done more systematically, a more extensive empirical investigation of people's situations, beliefs, and desires. Furthermore, understanding whether our purposes are legitimate may often require empirical investigation of what consequences would follow from the achievement of our goals, and the costs and benefits of the means taken to those ends.

Second, given an array of legitimate purposes, what concepts would serve them best? It requires empirical investigation to understand how our current concepts function, and the harms and benefits of using such concepts, by contrast with some other possible set of concepts. To draw upon Haslanger again, consider the goals of racial equality and the eradication of racism: will these purposes be better served by doing away with the concept of race altogether, by sticking with the concept(s) we already have, or by substituting a new concept of race? There are two potentially conflicting aspects to this issue: what would be the ideal final situation, and what is the most effective way of moving towards a better situation than our current one? Such questions are not easily answered a priori, and we must turn to the social sciences, rather than the natural sciences, for help.

I do not suggest that the social sciences can replace philosophical or other humanistic thinking in these areas, nor that we can draw sharp boundaries between the relevant disciplines or styles of thought. Nevertheless, Haslanger's framework, and her articulation of the nature and value of ameliorative projects, enables us to locate an important way in which more empirical study of social structures can help us pursue social metaphysics, without drawing false equivalences between the natural and social sciences. More generally, there are potentially fruitful connections between Haslanger's conception of ameliorative projects in philosophy, and longstanding debates about the role of values in social science (see e.g. Weber 1949, and for a recent overview Douglas 2014).

\section{Conclusion}

In his (2007), philosopher-economist Francesco Guala urges philosophers of social science towards more empirical methods. In his concluding remarks, he writes: 
Naturalism, more generally, is one of the very few theses which the majority of philosophers of science seem to agree upon. However, philosophers are still remarkably reluctant to 'put their research where their mouth is', so to speak. There are many ways in which philosophers of social science might (and probably will) try to resist the development of an empirical approach to social ontology... (975)

Imagine the same remarks transposed to the non-social realm: it is surely true that most philosophers of science are naturalists of one type or another, and there certainly is no such thing as a philosopher of physics who resists the development of an empirical approach to physical ontology. But this is not because of deep differences in the ways we approach physical and social ontology. Instead, it is because those philosophers who approach physical ontology non-naturalistically regard themselves as metaphysicians, rather than philosophers of science or philosophers of physics.

These issues of disciplinary self-identity cannot be ultimately significant, yet it is inevitable that they influence the ways in which we approach problems and questions regarding the social and non-social realms. In thinking about methodology for social ontology by way of comparison with methodology for non-social ontology, we can head off in different directions depending on whether we begin with philosophy of physics (or chemistry, or biology), general philosophy of science, or so-called 'analytic' metaphysics. And, as I have illustrated, there are issues which arise in connection with the social realm which have no clear analogues in the non-social realm-the coherence and potential attractiveness of ameliorative projects is one example.

Despite these challenges, there is scope for substantive further investigation of the role of social science within social metaphysics. Moreover this methodological inquiry promises to shed light not just on the proper approach to the social realm, but to questions about the proper role of empirical study within philosophy more generally.

Acknowledgements I am grateful to the organisers, co-panellists and audience at the colloquium Meta $^{2}$ physics: Analytic versus Naturalized Metaphysics, sponsored by the Society for the Philosophy of Science (GWP) and the DFG Research Group Causation, Laws, Dispositions, and Explanations, as part of the GAP.9 conference held in Osnabrück. In addition, I appreciate the helpful comments provided by two anonymous referees for this journal. My work on this paper was supported by a Major Research Fellowship from the Leverhulme Trust, which I very gratefully acknowledge.

Open Access This article is distributed under the terms of the Creative Commons Attribution 4.0 International License (http://creativecommons.org/licenses/by/4.0/), which permits unrestricted use, distribution, and reproduction in any medium, provided you give appropriate credit to the original author(s) and the source, provide a link to the Creative Commons license, and indicate if changes were made.

\section{References}

Barnes, E. (2014). Going beyond the fundamental: Feminism in contemporary metaphysics. In Proceedings of the Aristotelian Society CDIV.3 (pp. 335-51).

Callender, C. (2011). Philosophy of science and metaphysics. In S. French \& J. Saatsi (Eds.), The Continuum Companion to the Philosophy of Science (pp. 33-54). London: Bloomsbury Continuum.

Cooper, R. (2004). Why Hacking is wrong about human kinds. British Journal for the Philosophy of Science, 55(1), 73-85.

Douglas, H. (2014). Values in social science. In N. Cartwright \& E. Montuschi (Eds.), Philosophy of Social Science (pp. 162-182). Oxford: Oxford University Press.

Epstein, B. (2015). The Ant Trap. Oxford: Oxford University Press.

French, S. (1998). On the withering away of physical objects. In E. Castellani (Ed.), Interpreting Bodies (pp. 93-113). Princeton: Princeton University Press. 
Gilbert, M. (1989). On Social Facts. Princeton, NJ: Princeton University Press.

Gilbert, M. (2013). Joint Commitment: How We Make the Social World. Oxford: Oxford University Press.

Guala, F. (2007). The philosophy of social science: Metaphysical and empirical. Philosophy Compass, 2(6), 954-980.

Hacking, I. (1995). The looping effects of human kinds. In D. Sperber \& A. Premark (Eds.), Causal Cognition (pp. 351-394). Oxford: Clarendon Press.

Harding, S. (1991). Whose science? Whose knowledge?. Ithaca: Cornell University Press.

Haslanger, S. (2012). Resisting Reality. Oxford: Oxford University Press.

Hawley, K. (2006). Science as a guide to metaphysics? Synthese, 149(3), 451-470.

Laudan, L. (1981). A confutation of convergent realism. Philosophy of Science, 48(1), 19-49.

Maudlin, T. (2007). The Metaphysics Within Physics. Oxford: Oxford University Press.

Mills, C. W. (2007). White ignorance. In S. Sullivan \& N. Tuana (Eds.), Race and Epistemologies of Ignorance (pp. 11-38). Albany: SUNY Press.

Ostrom, E., \& Walker, J. A. (2005). Trust and Reciprocity: Interdisciplinary Lessons for Empirical Research. New York: Russell Sage Foundation.

Psillos, S. (1999). Scientific Realism: How Science Tracks Truth. London: Routledge.

Schmitt, F. F. (Ed.). (2003). Socializing Metaphysics. Lanham MD: Rowman and Littlefield.

Schrenk, M. (2017). Metaphysics of Science. London: Routledge.

Searle, J. (1995). The Construction of Social Reality. London: Penguin.

Sklar, L. (1981). Time, reality, and relativity. In R. Healey (Ed.), Reduction, Time, and Reality (pp. 129-142). Cambridge: Cambridge University Press.

Sztompka, P. (1999). Trust: A Sociological Theory. Cambridge: Cambridge University Press.

Tuomela, R. (2002). Social Ontology: Collective Intentionality and Group Agents. Oxford: Oxford University Press.

Weber, M. (1949). The Methodology of the Social Sciences (E. A. Shils \& H. A. Finch, Trans.). New York: Free Press.

Zak, P. A. (2012). The Moral Molecule: How Trust Works. London: Penguin. 